\title{
Outreach within the Bristol ChemLabS CETL (Centre for Excellence in Teaching and Learning)
}

\author{
Dudley E. Shallcross ${ }^{1}$, Tim G. Harrison ${ }^{1}$, Tim M. Obey ${ }^{1}$, Steve J. Croker ${ }^{1} \&$ Nick C. Norman ${ }^{1}$ \\ ${ }^{1}$ School of Chemistry, University of Bristol, UK \\ Correspondence: Professor Dudley Shallcross, School of Chemistry, Cantock's Close, University of Bristol, BS8 \\ 1TS, UK. Tel: 44-117-928-7796. E-mail: d.e.shallcross@bris.ac.uk
}

Received: October 30, 2012 Accepted: November 15, 2012 Online Published: January 25, 2013

doi:10.5539/hes.v3n1p39

URL: http://dx.doi.org/10.5539/hes.v3n1p39

\begin{abstract}
This paper presents an overview of the Bristol ChemLabS project. In particular, it describes the development and impacts of the outreach project within Bristol ChemLabS, the UK's Centre for Excellence in Teaching and Learning (CETL) in practical chemistry, and its continuation beyond the funded project. The major elements of working with both primary and secondary aged students, both within their schools and within the undergraduate teaching laboratories, are described together with aspects of the science teacher training. The teaching elements include school's conferences, workshops within the School of Chemistry as part of the Open Laboratory Programme, summer schools and overseas work. Evidence is provided that demonstrates the impact of this programme on enhancing positive attitudes toward science and further education for the school students, as well as providing enhancing and embedding learning opportunities for school students and their teachers. The very positive impacts on the postgraduate chemistry students that work alongside the School Teacher Fellow (STF), a secondary school teacher working within the School of Chemistry, is discussed and the vital role played by these postgraduates and the STF to the overall success of the Outreach Programme. Generating a sustainable (financially and in terms of personnel) Outreach programme of the size of Bristol ChemLabS (beyond the lifetime of the CETL programme) is a unique aspect amongst UK CETLs and the mechanism used to achieve this is also discussed.
\end{abstract}

Keywords: e-learning, outreach, practical chemistry, school teacher fellow, schools' conferences

\section{Introduction}

In 2005 the Higher Education Funding Council for England (HEFCE) invested approximately $£ 300$ million to establish 74 Centres for Excellence in Teaching and Learning (CETL) in Higher Education institutes in England (Chalkley, 2006). These CETLs (initiated by the UK Government White Paper "The future of Higher Education") were in part to redress the balance between the income associated with the Research Assessment Exercise (RAE) and the lack of income attracted by teaching excellence. Indeed, in the U.K., the introduction of the RAE exacerbated the perceived divide between the value of research and teaching, where a successful research return by a department within an institution has led to financial rewards, whereas the teaching equivalent, the Quality Assessment Authority's (QAA) review carried no financial benefit at all (Trowler et al., 2005). It is hard to reconcile these two processes running simultaneously and indeed Hannan and Silver (2000) highlight the detrimental effect on the status of teaching and learning in tertiary education institutes that this has caused. The CETL programme ran for five years in terms of funding, from 2005-2010, with the expectation that the CETLs would be sustainable beyond that time and keep running unaided. The 74 CETLs (HEFCE, 2011), spread across 54 institutions, covered a variety of themes including widening participation, employability, e-learning (Morales and Carmichael, 2007; Clouder et al., 2008), blended learning, active learning, work based learning, enquiry based learning, enterprise, literacy, etc. as well as subject themes including Physics (Lambourne, 2007), Chemistry (Harrison and Shallcross, 2010a; Harrison et al., 2011a; Shallcross et al., 2006; Shallcross et al., 2007c; Shallcross et al., 2010; Shaw et al., 2011), Medicine, Geography (Chalkley, 2006), Art, Media, Design, Engineering, Performing Arts, Computing, Statistics, Mathematics, Genetics, Languages and Veterinary Science. Now that the CETL initiative is over it is timely to look at its impact. In this paper we focus on the CETL dedicated to Chemistry called Bristol ChemLabS, housed within the School of Chemistry at the University of Bristol, providing an overview of what has been achieved. In particular in this paper we look at the impact of the 
Outreach Programme to schools, their teachers and the general public. In a future article we will assess the impact of the Bristol ChemLabS CETL on teaching and learning in chemistry.

\section{Overview of Bristol ChemLabS: Bristol Chemical Laboratory Sciences}

The focus of Bristol ChemLabS is on the teaching and learning of practical chemistry at undergraduate level and it is based in the School of Chemistry at the University of Bristol, UK. Bristol ChemLabS was established on $1^{\text {st }}$ April 2005 (Norman, 2007).

Part of the Bristol ChemLabS programme involved the complete refurbishment of the undergraduate teaching laboratories in the School of Chemistry at Bristol which included provision for a complete new inventory of equipment, instrumentation and IT facilities. In addition to this new infrastructure, a comprehensive overhaul of all aspects of what took place in the laboratory was also undertaken.

\subsection{The Need to Rethink the Part a Laboratory Plays in a Modern Chemistry Degree}

The Bristol experience of a traditional undergraduate teaching laboratory environment had been such that students would typically arrive at the laboratory to do an experiment without a clear idea of the practical techniques they would be using, the skills they would need, or the chemistry behind the practical. It was often only after the laboratory, during a write up, that they would generally start to work out what it was they had been doing all day (e.g. Rollnick et al. 2001a).

It was clear that students would gain much more from the laboratory experience if they knew what they would be doing before they arrived and effective preparation for the laboratory session would be the key to achieving this goal (Nicholls, 1999; Brattan et al., 1999; Pogačnik and Cigić, 2006). Additionally, the idea that a practical course could be sensibly assessed entirely on the basis of post-lab write ups was dismissed. One of the main innovations in Bristol ChemLabS therefore has been to shift the balance of work done outside the laboratory to before rather than after the practical class so that students are both better prepared and more confident. As part of this process, the Dynamic Laboratory Manual (DLM) was developed which is a multifunctional, e-learning tool designed to facilitate exactly this and much more besides (Harrison and Shallcross, 2008a; Harrison et al. 2009c).

Thus, as part of the Bristol ChemLabS experience, students are now required first to work through some background information about the experiment before they arrive at the laboratory. All the information they need for a particular experiment is contained in the DLM which is accessible online as a web-based resource. Crucially, therefore, the laboratories could be decoupled from, and unencumbered by, the lecture material and the order of its delivery. An important part of the pre-laboratory work centres on a set of multiple choice and multiple completion questions taken randomly from a question bank. These are summatively assessed electronically and form part of the overall assessment for that experiment, but immediate and informative feedback on any wrong answers is also provided. All experiments have a pre-lab component.

Further assistance with pre-lab preparation is provided by flash-based virtual instruments and equipment which are embedded within each experiment. However, some techniques are best illustrated by video and students find this a very useful way to construct a clear idea of what they will need to do in the laboratory. Some first year students have a very limited experience of glassware and general laboratory apparatus and seeing, for example, how to set up a Büchner filtration gives them confidence and saves them from having to ask a demonstrator who is then free to engage in much more productive activities with the students such as in-lab assessment (Rollnick et al., 2001b). Also contained within the DLM is a library of online tutorial material (much of it interactive) to assist students in their understanding of a range of analytical and spectroscopic techniques which they encounter in the laboratory.

An appreciation of safety issues is also an essential part of the laboratory experience and in the past, students have had to sign a safety form declaring that they understood the risks and hazards associated with the chemicals and apparatus for a particular experiment and the precautions which would need to be taken. Sadly, some students adopted a rather flippant "box ticking" attitude towards safety which it was important to improve upon. As part of the DLM, students are now asked a variety of questions concerning all aspects of safety for each experiment. These questions are delivered in a multiple choice or multiple completion format and students must score a minimum of $80 \%$. Students are thus forced to think about hazards and safe practices and a score of less than $80 \%$ after two attempts (different questions each time) requires that they see a demonstrator before they are allowed to start the experiment.

Academic staff and demonstrators are able to monitor how the students have performed on the pre-lab and safety tests using a database linked to the DLM, the safety marks being colour-coded green, amber or red to act as a 
visual aid in identifying how the students have performed. Tutors can also track their tutee's progress or indeed the progress of any student.

Other new features of the Bristol ChemLabS laboratory course include significant changes to what is expected in terms of report writing. Thus, a post-laboratory write up is no longer required for all experiments. When full laboratory reports are required (which they are for about one quarter of the experiments carried out), the students are assessed on their report writing skills having already been assessed on the basis of their pre-lab work and, in most cases, through assessment of their practical skills in the laboratory. They are expected to prepare their reports using a template constructed in the form of a scientific paper and are then able to upload their completed documents onto the DLM for assessment by staff that assign a mark and provide feedback. An assessment of this methodology on teaching and learning at undergraduate chemistry level will appear in a separate publication.

\section{The Outreach Strand of Bristol ChemLabS: Description, Assessment and Impact}

\subsection{Before the CETL}

Prior to the Bristol ChemLabS CETL programme, the School of Chemistry already had a range of outreach activities seeking to engage with teachers, schools and students of all ages to provide excellent teaching and learning opportunities in chemistry. The old laboratory was used for summer schools for school students but was underused outside of term time. A network of secondary school Chemistry teachers (called CHeMneT) was established in 2000 and by the award of the CETL was some 150 strong. The by-word of the Outreach program was sustainability and both financial constraints (each activity needed to be covered financially, even if that meant that the School of Chemistry bore the cost) and staff time constraints put a firm lid on what could be done. The programme was regional in nature, covering an approximate area of radius $100 \mathrm{~km}$ from Bristol at most and engaged with around 3,000 secondary school teachers and their students each year.

\subsection{During the CETL}

As part of the Bristol ChemLabS CETL project, a specific Outreach strand was established, allowing a full-time School Teacher Fellow or STF (Shallcross and Harrison, 2007b; 2007e) to be employed for the duration of the CETL (five years funded period). Initially, the plan was to have a one year secondment of a STF and then review the situation, but because the first incumbent was so successful it was decided to appoint them for the full five years, using CETL funds. In addition, $£ 30,000$ was available each year ( $£ 150,000$ in total) to the Outreach Director to spend on Outreach. Both factors were an incredible boost to the existing Outreach programme and allowed it to expand as rapidly and successfully as it did (see later). The STF concept was unique to Bristol ChemLabS, with the idea to have a full-time experienced secondary school teacher working alongside the Outreach Director. The STF concept proved so successful that the Royal Society of Chemistry adopted it as one of their main strands in their programs Chemistry: The Next Generation and Chemistry for Our Future (Tunney, 2009) and UK Higher Education Institutes have subsequently taken on STFs of their own in science subjects. However, from the very outset, the objective was to ensure that whatever was established during the CETL period would be sustainable, i.e., carry on afterwards (Harrison and Shallcross, 2010c).

\subsection{Open Laboratory Programme}

The School Teacher Fellow, being an experienced secondary school chemistry teacher, was able to design and implement a range of practicals for secondary school students (aged 11-18) and the newly refurbished laboratories were opened to schools every Wednesday during term time (they were not in use for undergraduate teaching) and also on a regular basis outside term time, in a theme termed the "Open Lab" programme (Harrison et al., 2011a). These practicals either mapped directly to the school curriculum but could not be carried out in schools due to either a lack of equipment or for health and safety concerns relevant to a school laboratory (usually relating to storage and disposal of chemicals). The fact that a School Teacher was behind the design of the practical made the impact much greater (knowledge of the curriculum, the ability of students and the likely timing of events within the school year) and in addition, the relevant health and safety forms required by school teachers to allow them to bring their schools to Bristol ChemLabS could be prepared by the STF. For school teachers to obtain permissions from their school to attend activities away from school in the UK has been problematic in the last decade, where health and safety and the "rarely cover" policy have made it easier to not bother. Therefore, making the school teacher's job easier was a real advantage to the success of the project. For example, during the school year 2010-11 some 33 laboratory days have been run, engaging with 1171 students. Such numbers exceeded the expectations of the original CETL programme by some way and so in that respect alone were a great success. However, further assessments of impact showed that teachers attitudes towards the laboratory programme were extremely favourable and that they believed that students benefitted greatly from not only the new practical experiences afforded but also the opportunity to experience University for some as young 
as 11 (Tuah et al., 2009; Shaw et al., 2010c). There was also some evidence to suggest that these activities also impacted directly on results, most notably in terms of spectroscopy at post-16 level (Harrison et al., 2010d). Here, students are expected to understand how to interpret data from a range of spectroscopic techniques (e.g. mass spectrometry, infra red spectroscopy and nuclear magnetic spectroscopy), but in the vast majority of cases, due to the high cost of these instruments, students never see them. It was found that the spectroscopy workshops had a significant effect on cognition. In addition, analysis of Polymer Chemistry days run throughout the year (Shaw et al., 2010a) showed that attitudes towards science were being altered in a positive manner. The Open Lab Programme was extended so that staff members from across the University could bring their children to work with them one day in the summer term and allow them to experience the Open Lab program. This initiative too had excellent feedback (Shaw et al., 2009) not only allowing school students to benefit from the experiences afforded by the programme but also allowing staff (all members not just academics) from other departments and faculties to learn a bit more about what happens in Chemistry and many fruitful collaborations have emerged in terms of teaching and education as a result, as well as breaking down artificial barriers between departments (e.g. departments in different faculties). Academics within the School of Chemistry would also remark in staff meetings and elsewhere that it was great to see the laboratories being used so much. The CETL monies allowed the Open Lab Programme to get underway (e.g., purchasing of dedicated laboratory equipment, e.g. small lab coats, glassware etc.) and after two years of trialling experiments with schools we began to charge a fee for the use of the laboratories. The level of fee was arrived at after considerable consultation and rather than driving schools away we found that more applied to come (teachers commented that the thought being that if you don't charge it is not worthwhile) and the number of non-attendances at events dropped to zero. Overnight the Open Laboratory Programme became self-financing and with a variety of grants that we and (disadvantaged) schools were able to obtain, no school was prevented from participating through a lack of funds (Harrison and Shallcross, 2010c). The Open Laboratory Programme has carried on beyond the CETL funding period, at the same level as during the first five years of the CETL and has attracted grants worth around $£ 200,000$ during this time and schools for all over South England and Wales have taken part (Harrison and Shallcross, 2010a). A further reason for the success of the Open Laboratory Programme has been the contribution of the technical staff (who all immersed themselves in the Outreach programme) and a cadre of some 300 postgraduate students during the course of the CETL and beyond who have been excellent laboratory demonstrators and role models for the school students and undergraduate students as part of the Undergraduate Ambassador Scheme (Harrison et al., 2009b; Harrison et al., 2011b). The numerous benefits to the postgraduate students themselves are outlined by Harrison et al., (2011b).

\subsection{Summer Schools}

In addition to summer schools run by the University of Bristol, Bristol ChemLabS built on the success of the Open Lab Programme to run summer schools for both UK and overseas students from Ireland, Malta, Spain, Italy and France (Harrison and Shallcross, 2008b; Harrison et al., 2009a; Shaw et al., 2010b). These summer schools are also now self-financing and have been running beyond the end of the CETL funded period. In addition to knowledge gathering, research has shown that students find them useful to help to decide whether further education is what they really want to progress to and if so then on which course to study at University (they find postgraduates a good source of reliable information) as well as the practical scientific benefits and the opportunities to work with students from other countries. These summer schools are now being run by Bristol ChemLabS in Singapore and South Africa for their school students using laboratories and facilities at Universities and science centres in the host country. In this way, Bristol ChemLabS have been able to disseminate best practice in the teaching of practical chemistry to other countries (Sunassee et al., 2011; Harrison et al., 2011c). Furthermore, "maths for chemists" summer schools run under a pilot scheme for the Royal Society of Chemistry has taken place. Here, students without pre-university level (in the UK "A" level) mathematics who are about to start a Chemistry degree (not necessarily at Bristol) have spent a residential week at Bristol ChemLabS and combined practical work that naturally leads to mathematical applications beyond compulsory leaving age mathematics (GCSE level in the UK) with tutorials in a most effective partnership for these students (Shallcross et al., 2011). Furthermore, summer schools have also been run for visually impaired adults that have challenged the use of practical chemistry, but through the use of talking meters, and using other senses than sight and sound such as smell and taste (e.g. making perfect chocolate) it has been viewed as an extremely positive challenge and experience for the providers as well as the students.

\subsection{DLM for Schools}

A major initiative that emerged from the Outreach programme was to develop a Dynamic Laboratory Manual (the University level version will be discussed and assessed more fully in a separate publication) for A level 
(Post-16) Chemistry to assist these students with practical work encountered at this level in school (Harrison and Shallcross, 2008a; Harrison et al, 2009d; Harrison and Heslop, 2010e). Once again, the value of the STF was clear, where all the problems that post-16 school students encounter with practical chemistry could be addressed by someone who had 25 years experience. The post-16 DLM also benefitted from being trialled by schools and teachers in the network (CHeMneT) and is now a commercial piece of software than generates an income that contributes to the sustainability of the Outreach programme. A more detailed assessment of the impact of the DLM for schools is currently being undertaken, but all preliminary studies have suggested that it has enhanced the laboratory experience (Harrison et al, 2009c).

\subsection{Lecture Programme}

A new initiative started during the CETL funded period was to hold termly conferences for school students. Here, an afternoon conference consisting of three lectures was started; two lectures would be given on a relevant theme for that particular age group of school students, followed by a lecture with many demonstrations to round off the conference. The success of this programme can be gauged by the fact that more conferences have been put on since a small fee was applied to attend. Again the STF has been crucial in working with lecturers (including postgraduate students who have had an opportunity to hone their science communication skills) to ensure that the scientific language used and the level adopted is appropriate (Tuah et al., 2009; Shaw et al., 2010c). From this lecture series emerged two lectures, "A Pollutant's Tale" (atmospheric chemistry and climate change; http://www.chemlabs.bris.ac.uk/outreach/A-Pollutant-Tale.html) and "A Chemical Delight" (colour chemistry and kinetics; http://www.chemlabs.bris.ac.uk/outreach/Chemical_Delight.html) that were written and presented by the Outreach Director and the STF that were then taken out to schools all across the UK and abroad (Tuah et al., 2010; Harrison et al., 2011c). These lectures have been performed on 750 occasions to an estimated audience of 150,000 people over 6 years on 5 continents in their various forms. Research (Tuah et al., 2010; Harrison et al., 2011c) has shown that these lectures are more than entertaining and inspirational for school students, because of the scaffolding of knowledge and appropriate language and concepts used, students learn and have reinforced, important scientific concepts, that stay with them.

\subsection{Teachers}

CHeMneT has increased since 2005 from $\sim 150$ to around 750 teachers and grows without any advertising. In addition there are teachers from abroad who have joined in the last six years. A practical course for non-chemistry specialist teachers to help them overcome any trepidations of carrying out practicals was so successful that it was also adopted by the Royal Society of Chemistry and expanded countrywide. During 2010-11 518 teachers attended 9 Bristol ChemLabS CPD sessions on topics from Climate Change to practical work with smart materials for 14-16 year olds.

As well as masterclasses for teachers, a new innovation has been the writing of cutting-edge research articles for a school audience (see Appendix). These articles have had several impacts, first, they have challenged academics and postgraduate students to write for a school audience and this has improved their ability to communicate with a general audience. Second, it has raised the profile of the research within the department and finally the articles have been well received by school students, their teachers and the general public, where a series on climate change alone has attracted over 250,000 downloads and has been translated into eight languages.

\subsection{Primary}

Given the fact that there are approximately 19,000 primary schools in the UK before the CETL award, engagement was restricted to just a handful of primary schools. On the start of the CETL, a primary circus of chemistry experiments (Griffin et al., 2006; Griffin et al., 2007; Harrison et al., 2010b; Rivett et al., 2009), still unique to Bristol ChemLabS, were devised and $£ 4000$ worth of equipment and lab coats were purchased. Once more, postgraduate students and the STF were prominent in going out to local primary schools and running workshops. A short term formal assessment has been able to show that the Bristol ChemLabS Primary Outreach programme is able to generate interest and enthusiasm within young children towards science while educating teaching them on several basic ideas and concepts (Haslie, 2010).

A long term formal assessment of the impact of primary outreach has not been conducted but informal assessments through teacher and student responses (Rivett, 2009) show that such interventions, repeated on a regular basis (at least annually) do start to impact of students attitudes to science in a positive way. A competition called Chem@rt (Rivett et al., 2009) was set up where images developed from research in the School of Chemistry were collected in a gallery (around 12 chosen each year out of up to 30 entered each year) and made available to primary teachers with accompanying notes on the image. These notes were written in appropriate scientific language for primary school level, using concepts used at this level to describe the images (a real test 
of science communication). The teachers could then use the images as stimulus material for lessons or to stimulate the writing of poetry or prose. During the course of the Chem@rt competition some outstanding pieces of work have been produced, showing great insight into the science behind the image and making the cross-over between science and literacy (Rivett et al., 2009).

\subsection{Overseas Engagement}

Bristol ChemLabS Outreach activities have taken place on 5 continents. At Penn State University, USA, teacher training events are being planned having already carried out schools outreach. In South Africa, graduate and postgraduate training has taken place allowing participants to be able to deliver lecture demonstrations (Sunassee et al, 2011) and other practical chemistry outreach events have taken place at Rhodes University and at the Sci-Bono Discovery Centre, Johannesburg. Teacher training has, and will continue to take place in South Africa. For the last 5 years in Singapore a Bristol ChemLabS team has delivered a winter chemistry school programme for local school students working alongside members of the chemistry department of the National University of Singapore.

\subsection{Other Indicators of Success}

The outreach programme has attracted; 1 international award, 10 national awards, 7 University of Bristol Awards as well as receiving around $£ 400,000$ in UK grants and around $£ 100,000$ in EU funding (Gros, 2008; Mustafa et al, 2010)). It is now financially sustainable through a mixed model of funding streams (Harrison et al., 2011c), such as direct grant income, sales of software, charging for activities, donations and other sources. Many initiatives, STF, Open Labs Programme, DLM, primary circus and lecture demonstrations have been disseminated to other groups and other countries. Although recruitment was not the focus of the Outreach program, the number of students applying to the School of Chemistry that had engaged with the Outreach programme was significantly higher than those that did not (Shaw et al, 2011), i.e. the Outreach Programme had a positive impact on those students engaged to apply for Chemistry at Bristol.

\subsection{Key Aspects of the Success of the Bristol ChemLabS Outreach Programme}

There is no doubt that having five years of funding made a significant difference. It allowed the Outreach Programme to take on the STF and have two to three years where new ideas could be trialled before settling on a plan for sustainable development beyond that point. The appointment of the STF was the single most important factor in generating a successful Outreach Programme but there were other very important factors too. First, the culture of the department and in particular the senior management team (SMT) was critical. The SMT put their support behind the Outreach Programme from the outset and encouraged academics in the department to support the project (in particular to allow their postgraduate students to be involved). Without a supportive senior management team, the project would have been diminished; they allowed the laboratories and other facilities to be used, encouraged its support and allowed technical staff to be involved too. Second, the role of the technical staff and postgraduate students in supporting the programme was essential. The School of Chemistry at Bristol University is fortunate to have a large pool of postgraduate students and whether the breadth and range of activities could be repeated with a smaller pool is questionable. Third, the previous five years of outreach meant that the project hit the ground running and in particular the teacher network CHeMneT was invaluable to the development and success of the project, in particular the development of the DLM. Fourth, having funding that could be invested in projects so that potential co-funders could contribute part of the total (typically 50\%) meant that new funding streams were opened up and success in winning further funding clearly made a difference to the overall success. Finally, the interaction with groups outside the UK made an incredible difference. Funding from the CETL allowed those interactions to build to a point where they were able to be long lasting and having that perspective from another country (culture and education) was incredibly important. Effective advisory boards were a feature of this CETL (Shallcross et al., 2010a) and they also made important contributions to the success of the programme.

\section{Conclusion}

The aims of the Bristol ChemLabS CETL project to raise standards in practical chemistry through the creation of a national resource for innovation in the teaching and learning of practical experimental science have been met. Qualitative feedback indicates that the effects on learning and teaching have been significant.

The refurbishment of the undergraduate laboratories was completed on schedule and has created a world-class environment for the teaching of practical chemistry. The laboratories are equipped to the very highest standard providing demonstrable benefits to both undergraduate students and staff. The introduction of innovative new teaching methods has also proved highly successful. An on-line web-based Dynamic Laboratory Manual has 
been created for undergraduate students, allowing the introduction of new methods of assessment (e-assessment) and mechanisms for rapid feedback that are both more effective and more efficient in terms of staff and student time.

The impact of the developments in teaching and learning methods within the School of Chemistry has spread beyond just practical courses. The project has raised the status of teaching and learning and led to innovations, such as the greater use of e-learning, in other areas of the chemistry curriculum particularly in relation to online tutorial support for lecture-based material. This has already spread to other University of Bristol departments in the Faculty of Medical Sciences (Lloyd et al, 2009, Barnes et al, 2008, Langton et al 2009, Macmillan \& Langton, 2009) and to a number of chemistry departments worldwide.

The programme of outreach activities has proved highly successful as described. The appointment of an experienced School Teacher Fellow was pivotal, but so was the support of the senior management team, postgraduate students, technical staff and other support staff.

Bristol ChemLabS has also been active in exploring ways of ensuring that its achievements are sustainable with success in obtaining commercial support and also by way of the production of a Dynamic Laboratory Manual for schools (A-Level Chemistry LabSkills) and other universities and the development of cost neutral outreach activities.

\section{External Comment}

Professor Davies-Coleman former head of Department of Chemistry at Rhodes University in Grahamstown, South Africa and recently appointed Dean of Science at the University of Western Cape was Bristol's initial contact in Africa. He commented as follows about the Bristol Overseas Outreach project, "I had no idea that my initial chance meeting with Shallcross and Harrison at the Science Festival held annually in Grahamstown would lead to an ever-expanding collaboration in which we would revolutionize the practice of outreach in chemistry at Rhodes University and how this would feed back into a radical review of our teaching and learning strategies at the school/university interface both at Rhodes and further afield in South Africa. Through an ongoing collaboration with Bristol ChemLabS involving staff and student interchange between the Universities over a period of three years approximately thirty Rhodes post-graduate students led by Rhodes staff member Joyce Sewry have become enthusiastically involved informing both urban and rural communities about the science behind climate change through the universally accessible "A Pollutant's Tale" lecture presentation. Not only have the student's benefitted from "talking science" in public but the Department's profile in community engagement rose rapidly within the University leading to Sewry being awarded the Vice Chancellor's distinguished community engagement award in 2011. As our collaboration with Bristol ChemLabS grew Rhodes University became the first University if Africa to roll out the LabSkills programme which has proved to be an invaluable tool to rapidly meet the deficits in practical skills common amongst students entering the university from an under-resourced school system in which access to practical chemistry is often not possible. The South African journey with Bristol ChemLabS is far from over and other Universities in South Africa are beginning to tap into the expertise, experience and resources so freely and enthusiastically shared by our colleagues at Bristol University.

\section{Acknowledgments}

We thank HEFCE for funding for Bristol ChemLabS. Dudley Shallcross thanks the Higher Education Academy for a National Teaching Fellowship under whose auspices various elements of this work was carried out. We thank Prof. Paul Wyatt for useful conversations during the preparation of this manuscript and to the many collaborators involved in the Bristol ChemLabS Outreach project whose contributions have been valued greatly.

\section{References}

Barnes, S. D., \& Langton P. D. (2008). On-line histology quizzes on a virtual microscope. Proceedings of the Physiological Society, 11, PC56.

Brattan, D., Mason D., \& Rest A. J. (1999). Changing the nature of physical chemistry practical work, University Chemistry Education, 3, 59-63.

\begin{tabular}{|c|c|c|c|c|c|}
\hline $\begin{array}{l}\text { Bristol } \\
\text { http }\end{array}$ & $\begin{array}{l}\text { ChemLabS. } \\
\text {.chemlabs.bris.ac.uk/outreach/ }\end{array}$ & $\begin{array}{l}\text { Retrieved } \\
\text { ant-Tale.htm }\end{array}$ & August & 2011 & from \\
\hline $\begin{array}{l}\text { Bristol } \\
\text { http }\end{array}$ & $\begin{array}{l}\text { ChemLabS. (2011). } \\
\text {.chemlabs.bris.ac.uk/outreach/C }\end{array}$ & $\begin{array}{l}\text { Retrieved } \\
\text { 1_Delight.ht }\end{array}$ & August & 2011 & from \\
\hline
\end{tabular}


62, 155-157. http://dx.doi.org/10.1111/j.1745-7939.2006.00067.x

Clouder, L., Oliver, M. \& Tait, J. (2008). Embedding CETLs in a performance-oriented culture in higher education: Reflections on finding creative space. British Ed. Res. Journal, 34(5), 635-650. http://dx.doi.org/10.1080/01411920802224154

Gosling, D., \& Hannan, A. (2007). Responses to a policy initiative: The case of Centres for Excellence in Teaching and Learning. Studies in Higher Education, 32(5), 633-646. http://dx.doi.org/10.1080/03075070701573799

Griffin, A., Harrison T. G., \& Shallcross, D. E. (2006). Perfume chemistry, sexual attraction and exploding balloons: University activities for school. Science in School, 3, 48-51.

Griffin A., Harrison T. G., \& Shallcross D. E. (2007). Primary circuses of experiments. Science in School, 7, 28-32.

Gros, N. (2008). Analchemvoc 2. Retrieved September 1, 2011 from http:// www.kii2.ntf.uni-lj.si/analchemvoc2/file.php/1/HTML/experiments.htm

Gros, N., Harrison T. G., Drusany, I. S., \& Dolinar, A. K. (2010). Spectrometry at school: Hands-on experiments. Science in School, 14, 42-47.

Hannan, A., \& Silver, H. (2000). Innovating in higher education: Teaching, learning and institutional cultures. Buckingham: Open University Press.

Harrison, T. G., \& Heslop, W. J. (2010e). How to get the most out of chemistry practical work. Chemistry in Action, 90, 45-48.

Harrison, T. G., Hanford, K. L., Cheesman, B. T., Kaur, G., Franklin, S. D., Laurain, A. M. C., Medley, M. I., Rivett, A. C., Sellou, L., Shallcross, K. L., Shaw, K. E., Williams, S. J., \& Shallcross, D. E. (2011b). The many positive impacts of participating in outreach activities on postgraduate students. New Directions in the Teaching of Physical Sciences, Higher Education Academy UK Physical Sciences Centre, 7, 13-18.

Harrison, T. G., \& Shallcross, D. E. (2008a). A chemistry dynamic laboratory manual for schools. Chemistry in Action, 86, 20-22.

Harrison, T. G., \& Shallcross, D. E. (2010c). Towards sustainable public engagement (outreach). New Directions in the Teaching of Physical Sciences, Higher Education Academy UK Physical Sciences Centre, 6, 41-46.

Harrison, T. G., \& Shallcross, D. E. (2010a). What should be Expected of Successful Engagement between Schools, Colleges and Universities? School Science Review, 91(35), 97-102.

Harrison, T. G., Davey, W., \& Shallcross, D. E. (2011a). Making better and wider use of undergraduate teaching laboratories in the UK. New Directions in the Teaching of Physical Sciences, Higher Education Academy UK Physical Sciences Centre, 7, 79-84.

Harrison, T. G., Hughes, L., \& Shallcross, D. E. (2009a). Jersey Schools Science Week: An outreach case study. New Directions in the Teaching of Physical Sciences, Higher Education Academy UK Physical Sciences Centre, 4, 30-33.

Harrison, T. G., Shallcross, D. E., Heslop, W. J., Eastman, J. R., \& Baldwin, A. (2009c). Transferring Best Practice from Undergraduate Practical Teaching to Secondary Schools: The Dynamic Laboratory Manual. Acta Didactica Napocensia, 2(1), 1-8.

Harrison, T. G., Shallcross, D. E. (2008b). A three-way collaboration: Ireland, the UK and Malta. Science in School, 10, 6 .

Harrison, T. G., Shallcross, D. E., Norman, N. C., Sewry J. D., \& Davies-Coleman, M. T. (2011c). Publicising chemistry in a multi-cultural society: The Bristol and Rhodes Universities chemistry outreach experiences. Accepted by the South African Journal of Education.

Harrison, T. G., Shallcross, D. E., Shaw, A. J., Medley, M. I., \& Bell, Z. (2010b). The sweet smell of success: Primary pupils study fragrance science at a leading university chemistry department. Romanian Journal of Education, 1(2), 75-80.

Harrison, T. G., Shaw, A. J., Shallcross, K. L., Williams, S. J., \& Shallcross, D. E. (2010d). School-university partnerships: Lessons learned from 10 years of spectroscopy for teachers and post 16 students. New Directions in the Teaching of Physical Sciences, Higher Education Academy UK Physical Sciences Centre, $6,72-76$. 
Harrison, T. G., Smith, D. M., \& Shallcross, D. E. (2009b). Final year School Projects: The Bristol ChemLabS Use of the Undergraduate Ambassador Scheme. Acta Didactica Napocensia, 2(2), 35-40.

Harrison, T. G. (2006). Chemistry that gets right up your nose. Chemistry Review, 16(2), 2-6.

Haslie, S. H. Hj. (2010). An evaluation of Bristol ChemLabS primary outreach programme using the learning taxonomiesm (Mater's thesis). University of Bristol, UK.

HEFCE. (2011). Retrieved August 10, 2011 from http://www.hefce.ac.uk/learning/tinits/cetl/final/cetllist.doc

Lambourne, R. (2007). Laboratory-based teaching and the physics innovations centre for excellence in teaching and learning. Eur. J. Phys., 28, S29-S36. http://dx.doi.org/10.1088/0143-0807/28/3/S03

Langton, P. D., Macmillan, F. M., Helyer, R., Lloyd, E., Headley, P. M., \& Harris, J. R. (2009). Successful implementation of mandatory on-line pre-laboratory quizzes across several first year Units in Physiology: Why, what, when and how much? Proceedings of the Physiological Society, 15, SA32.

Lloyd, E., Coverdale, G., Thompson, A., \& Helyer, R. J. (2009). Validating the Human Patient Simulator (HPS) as an educational tool: Determining the relationship between alveolar ventilation and the alveolar partial pressure of carbon dioxide. Proceedings of the Physiological Society, 15, PC73.

Macmillan, F. M., \& Langton, P. D. (2008). Introduction of on-line pre-practical quizzes as a means to increase undergraduate student engagement with laboratory practical classes. Proceedings of the Physiological Society, 11, PC55.

Morales, R., \& Carmichael, P. (2007). Mapping academic collaboration networks: Perspectives from the first year of the reusable learning objects CETL. J. Universal Comp. Sci., 13(7), 1033-1041.

Mustafa, E., Böyük, U., \& Harrison, T. G. (2010). Modular mobile education: Science experiments: Evaluation $\begin{array}{lllll}\text { report. } & \text { Retrieved } & \text { September } & 911 & \text { from }\end{array}$ http://mobilim.bozok.edu.tr/en/Mobilim_Evaluation_Report_(En).pdf

Nicholls, B. S. (1999). Pre-laboratory support using dedicated software. University Chemistry Education, 3, 22-27.

Norman N. C. (2007). Bristol ChemLabS Interim Evaluation Report. Retrieved September 9, 2011 from http://www.chemlabs.bris.ac.uk/InterimReviewWeb.pdf

Pogačnik, L., \& Cigić, B. (2006). How to motivate students to study before they enter the lab. Journal of Chemical Education, 83, 1094-1098. http://dx.doi.org/10.1021/ed083p1094

Rivett, A. C., Harrison, T. G., \& Shallcross, D. E. (2009). The art of chemistry. Primary Science Review, 110, 9-13.

Rivett, A. C. (2009). A study into the feasibility and validity of using alternatives to questionnaires to evaluate the impact of a selection of physics \& chemistry science communication activities (Master's thesis). University of Bristol, UK.

Rollnick, M., Lubben, F., Dlamini, B., \& Lotz, S. (2001a). Views of South African chemistry students in university bridging programmes on the reliability of experimental data. Res. in Sci. Ed., 31, 553-573.

Rollnick, M., Zwane, S., Staskun, M., Lotz, S., \& Green, G. (2001b). Improving Pre-Laboratory Preparation of First Year University Chemistry Students. Int. J. Sci. Edu., 23, 1053-1071. http://dx.doi.org/10.1080/09500690110038576

Shallcross, D. E., \& Harrison, T. G. (2007a). Lectures: Electronic presentations versus chalk and talk, a chemist's view. Chemistry Education Research and Practice, 8, 73. http://dx.doi.org/10.1039/b6rp90021f

Shallcross, D. E., \& Harrison, T. G. (2007b). A Secondary School Teacher Fellow within a university chemistry department: The answer to problems of recruitment and transition from secondary school to University and subsequent retention? Chemistry Education Research and Practice, 8, 101-104.

Shallcross, D. E., \& Harrison, T. G. (2007c). Why bother taking University led Chemistry Outreach into Primary Schools? Bristol ChemLabS experience. New Directions in the Teaching of Physical Sciences, Higher Education Academy UK Physical Sciences Centre, 3, 41-44.

Shallcross, D. E., \& Harrison, T. G. (2007e). The impact of School Teacher Fellows on teaching and assessment at tertiary level. New Directions in the Teaching of Physical Sciences, Higher Education Academy UK Physical Sciences Centre, 3, 77-78. 
Shallcross, D. E., \& Walton, G. (2007d). What's in a grade? The real meaning of mathematics grades at GCSE and A level. New Directions in the Teaching of Physical Sciences, Higher Education Academy UK Physical Sciences Centre, 3, 73-76.

Shallcross, D. E., Allan, N. L., Shallcross, K. L., Croker, S. J., Smith, D. M., May, P. W., Price, G., \& Harrison, T. G. (2011). Solving the maths problem in Chemistry: The impact of a pre-university maths summer school on year 1 and year 2 Physical and Theoretical Chemistry. New Directions in the Teaching of Physical Sciences, Higher Education Academy UK Physical Sciences Centre, 7, 58-62.

Shallcross, D. E., Harrison, T. G., Norman, N. C., \& Wyatt, P. J. (2010). The importance of advisory boards in undergraduate chemistry teaching. Romanian Journal of Education, 1, $61-66$.

Shallcross, D. E., Harrison, T. G., Wallington, S., \& Nicholson, H. (2006). University and Primary School Links, the Bristol ChemLabS Experience. Primary Science Review, 94, 19-22.

Shaw, A. J., Harrison, T. G., \& Shallcross, D. E. (2010c). What Value has Chemistry Outreach by a University department to secondary schools? Teacher Perceptions of Bristol ChemLabS Outreach Events. Acta Didactica Napocensia, 3(3), 15-23.

Shaw, A. J., Harrison, T. G., Croker, S. J., Medley, M., Sellou, L., Shallcross, K. L., Williams, S. J., \& Shallcross, D. E. (2010a). University-School partnerships: Polymer Chemistry days run at a University for 14-15 year olds and their impact on attitudes to Science. Acta Didactica Napocensia, 3(1), 19-26.

Shaw, A. J., Harrison, T. G., Croker, S. J., Medley, M., Sellou, L., Shallcross, K. L., Williams, S. J., \& Shallcross, D. E. (2010b). University-School partnerships: On the impact on students of Summer Schools (for school students aged 17-18) run by Bristol ChemLabS. Acta Didactica Napocensia, 3(4), 35-48.

Shaw, A. J., Harrison, T. G., Medley, M., \& Shallcross, D. E. (2009). Chemistry Inreach: Engaging with University Employees' Children within a Chemistry Department. Acta Didactica Napocensia, 2(4), 107-112.

Shaw, A. J., Harrison, T. G., Shallcross, K. L., Williams, S. J., \& Shallcross, D. E. (2011). On the impact of the Bristol ChemLabS' Outreach program on admissions to the School of Chemistry. New Directions in the Teaching of Physical Sciences, Higher Education Academy UK Physical Sciences Centre, 7, 22 -26.

Sunassee, S. N., Young, R. M., Sewry, J. D., Harrison, T. G., \& Shallcross, D. E. (2011). An Impact Assessment of Atmospheric Chemistry Demonstrations In Schools In The Western Cape Province Of South Africa. Submitted to South African Journal of Chemistry.

Trowler, P., Fanghanel, J., \& Wareham, T. (2005). Freeing the chi of change: The Higher Education Academy and enhancing teaching and learning in higher education. Studies in Higher Education, 30(4), 427-444. http://dx.doi.org/10.1080/03075070500160111

Tuah, J., Harrison, T. G., \& Shallcross, D. E. (2009). The advantages perceived by schoolteachers in engaging their students in university-based chemistry outreach activities. Acta Didactica Napocensia, 2(3), 31-44.

Tuah, J., Harrison, T. G., \& Shallcross, D. E. (2010). A review of the use of demonstration lectures in the promotion of positive attitudes towards, and the Learning of Science with reference to a "A Pollutant's Tale", a demonstration lecture on air quality and climate change. Romanian Journal of Education, 1(3-4), 93-102.

Tunney, J. (2009). A Legacy for Chemistry Education. New Directions in the Teaching of Physical Sciences, Higher Education Academy UK Physical Sciences Centre, 5, 7-11.

\section{Appendix}

\section{Articles written for a school audience on cutting-edge research}

Ashfold, M. N. R., Orr-Ewing, A. J., \& Harrison, T. G. (2011). Lasers in Chemistry. Chemistry Review, 21(1).

Cheesman B., \& Harrison, T. G. (2010). Silicon and silicone. Chemistry Review, 19(4), 2-5.

Grant A., Harrison, T. G. (2011). Out of thin air. Poison in the air: Atmospheric carbon monoxide. Chemistry Review, 20(3), 16-20.

Harrison, T. G., Shallcross, D. E., \& Henshaw, S. (2006). Detecting $\mathrm{CO}_{2}$ - the hunt for greenhouse-gas emissions. Chemistry Review, 15(3), 27-31.

Kaur, P., \& Harrison, T. G. (2009). Life in Extreme Environments. Chemistry Review, 18(3), 20-24. 
Mosadeghzad, Z., \& Harrison, T. G. (2009). Natural products: Chemistry and medicinal drugs. Chemistry Review, 19(1), 25-31.

Percival, C. J., Shallcross, D. E., \& Harrison, T. G., (2006). Catching the cheats - detecting drugs in sport. Chemistry Review, 15(4), 24-27.

Sellou, L., \& Harrison, T. G. (2008). Big smile! Toothpaste chemistry. Chemistry Review, 17(2), 17-21.

Shallcross, D. E. (2006a). Dirty Air. Education in Chemistry, 43, 131-135.

Shallcross, D. E., \& Harrison, T. G. (2007c). Climate change made simple. Physics Education, 42, 592-597. http://dx.doi.org/10.1088/0031-9120/42/6/005

Shallcross, D. E., \& Harrison, T. G. (2008a). Climate change modelling in the classroom. Science in School, 9 , 28-33.

Shallcross, D. E., \& Harrison, T. G. (2008b). Practical demonstrations to augment climate change lessons. Science in School, 10, 46-50.

Shallcross, D. E., \& Harrison, T. G. (2009b). Hydrogen in the Earth's atmosphere. Chemistry Review, 19, 2-6.

Shallcross, D. E., \& Harrison, T. G. (2010b). Out of thin air. From volcanoes to sea salt: Atmospheric sulfur. Chemistry Review, 20(1), 16-19.

Shallcross, D. E., \& Harrison, T. G. (2010c). Out of thin air. Atmospheric nitrogen. Chemistry Review, 20(2), 7-9.

Shallcross, D. E., Harrison, T. G., Henshaw, S. J., \& Sellou, L. (2009a). Fuelling interest: Climate change experiments. Science in School, 11, 38-43.

Shallcross, D. E., Harrison, T. G., Henshaw, S. J., \& Sellou, L. (2009c). Looking to the heavens: Climate change experiments. Science in School, 12, 38-43.

Wajrak, M., \& Harrison, T. G. (2011). Arsenic in drinking water - the silent killer. Accepted by Chemistry Review. 